\title{
Perceptions, relationships, societal contexts, and previous decisions influenced women's decisions about hormone replacement therapy
}

Marmoreo J, Brown JB, Batty HR, et al. Hormone replacement therapy: determinants of women's decisions. Patient Educ Couns 1998 Mar;33:289-98.

\section{Question}

How do menopausal women make decisions about whether to start, stop, or continue hormone replacement therapy (HRT)?

\section{Design}

Focus groups.

\section{Setting}

Toronto, Ontario, Canada.

\section{Participants}

56 postmenopausal women (44-73 y) who responded to a poster or newspaper advertisement. Most were white, worked full time or part time (57\%), and had university or postgraduate degrees $(50 \%)$. Women with medical conditions that contraindicated HRT (eg, breast cancer) were excluded.

\section{Methods \\ Women were assigned to 1 of 8 focus groups based on HRT sta- tus (2 groups of women who had never used HRT, 2 groups who had started and stopped HRT, 1 group who had been using HRT for $\geqslant 1 \mathrm{y}$, and 3 mixed groups). A family physician and a psychologist facilitated the groups. Each 2 hour session was observed by $\geqslant 1$ of the authors, audiotaped, and transcribed ver- batim. Analysis was concurrent with data collection.}

\section{Main findings}

Women's decisions about HRT were influenced by 4 spheres, among which there was a dynamic interplay. As well, the positive or negative intensity of a sphere, referred to as the weighted influ- ence, could alter the decision making process. The first sphere, internal influences, referred to women's internal perceptions and feelings, and included symptoms of menopause and benefits and negative side effects experienced with HRT use. The second sphere, interpersonal relationships, included the patient-physician relationship, relationships with family members (particularly health status and history of the mother and the sexual relationship with a partner), and the influence of friends and information networks (for identifying alternative treatments and support). The nature of the patient-physician relationship was important, with good communication characterised by listening, openness, information giving, and mutual discussion. The third sphere, external influences, related to the larger societal context, specifically, agism and sexism. The fourth sphere, consequences, referred to the results of the women's treatment decisions. The women accepted responsibility for their choices, and were open to changing directions if research evidence supported a change.

\section{Conclusions}

Menopausal women's decisions about starting, stopping, or continuing hormone replacement therapy were influenced by internal perceptions and feelings; interpersonal relationships with physicians, family members, friends, and information networks; external societal contexts including sexism and agism; and the consequences of treatment decisions. The positive or negative intensity of any sphere could alter decision making.

Source of funding: Women's College Hospital Research Fund.

For correspondence: Dr J B Brown, Centre for Studies in Family Medicine, Thames Valley Family Practice Research Unit, University of Western Ontario, London, Ontario N6G 4X8, Canada. Fax +1 5198585029.Email jbrown@julian.uwo.ca

\section{Commentary}

The study by Marmoreo et al addresses the complex and multifaceted process women go through when deciding to begin HRT. The authors state that despite strong medical advice in favour of HRT, only $11-15 \%$ of women $\geqslant 50$ years of age actually fill their prescriptions. Rather than viewing postmenopausal women who decline HRT as "non-compliant," practitioners can better assist women to make decisions about HRT by bringing together their medical and social science knowledge, the patient's personal history, and specific concerns.

Strengths of the study include the large number of focus groups, the use of 2 facilitators for each group with the additional safeguard of $\geqslant 1$ observer for each group, and the analysis of data concurrent with data collection to ensure saturation of themes. The qualitative design allowed the participants to describe the factors affecting their decision making in their own words and thus eliminated bias caused by preconceptions held by the researchers.

There are, however, several possible limitations to the usefulness of these findings in practice. The transferability of the findings is limited by the race (mainly white) and educational level (50\% university or postgraduate degrees) of the participants. Also, the factors within the spheres of influence were not weighted relative to each other.

The influence of the media, which was found to be important in another study, ${ }^{1}$ did not emerge in this study, and sources of information were not addressed in any depth. These limitations illustrate the lack of information on this topic and provide direction for further research.

This study offers insight for primary care nurses and nurse practitioners into how women view the complex issues influencing their decisions about HRT and documents the importance of the patient-provider relationship in this decision making. The study findings emphasise the importance of ensuring that menopausal women are given the time to discuss these complex issues and that care providers listen carefully to them.

\footnotetext{
Elizabeth S Carlson, RNC, WHNP, PhD Assistant Professor Loyola University, Chicago Chicago, Illinois, USA

1 Andrist LC. Health Care Women Int 1998;19:243-60.
} 